\title{
QUEM CONTROLA O ORÇAMENTO? APONTAMENTOS SOBRE O TIMING DE LIBERAÇÃO DAS EMENDAS ORÇAMENTÁRIAS INDIVIDUAIS
}

\section{WHO CONTROLS THE BUDGET? REMARKS ON THE RELEASE TIMING OF INDIVIDUAL BUDGETARY AMENDMENTS}

\author{
Raul Wesley Leal Bonfim* \\ Vítor Eduardo Veras de Sandes-Freitas**
}

\begin{abstract}
Resumo
Este artigo tem por objetivo analisar a influência do Poder Executivo sobre o ciclo financeiro e orçamentário das emendas parlamentares individuais. É consenso na literatura, que o Executivo possui o domínio legal sobre o orçamento e, consequentemente, sobre a liberação das emendas orçamentárias. No entanto, ainda não foram explorados quais mecanismos do orçamento permitem ao Executivo controlar o timing e o volume dos recursos liberados. A partir disso, questiona-se: dado o formato do ordenamento financeiro e orçamentário brasileiro, no qual as emendas individuais estão submetidas, como o Poder Executivo consegue influenciar o volume de recursos pagos referentes às emendas individuais solicitadas pelos deputados federais brasileiros na Lei Orçamentária Anual (LOA)? Os achados deste artigo apontam que o ciclo financeiro e orçamentário, que compreende as emendas individuais, caracteriza-se pelo seu alto grau de subordinação ao Poder Executivo. Dito de outra forma, o Poder Executivo é capaz de dissipar as preferências do Poder Legislativo alterando os valores das emendas individuais aprovadas na LOA, em todos os estágios do seu ciclo financeiro e orçamentário.
\end{abstract}

Palavras-chave: Executivo; Legislativo; Orçamento Federal; Emendas Parlamentares Individuais.

\begin{abstract}
The aim of this paper is to analyze the influence of the Executive on the financial and budgetary cycle of individual parliamentary amendments. There is a consensus in the literature that the Executive has the legal command over the budget and, consequently, over the release of budget amendments. However, which budget mechanisms allow the Executive to control the timing and quantity of resources release has not been explored yet. Thus, it is questioned: given the format of the Brazilian financial and budgetary planning, in which the individual amendments are submitted, how can the Executive branch influence the amount of funds paid for individual amendments requested by the Brazilian federal deputies in the Annual Budgetary Law (LOA)? The findings of this paper indicate that the financial and budgetary cycles comprising the individual

\footnotetext{
* Doutorando em Ciência Política (Unicamp/Brasil). E-mail: raulbonfim16@gmail.com.

** Professor Adjunto da Universidade Federal do Piauí (UFPI/Brasil). Doutor em Ciência Política pela Universidade Estadual de Campinas (Unicamp/Brasil).E-mail: vitorsandes@ufpi.edu.br.
} 
amendments are characterized by a high degree of subordination to the Executive. In other words, the Executive is able to dissipate the preferences of the Legislative by altering the values of individual parliamentary amendments approved in LOA at all stages of its financial cycle.

Keywords: Executive; Legislative, Federal Budget; Individual Parliamentary Amendments.

\section{Introdução}

Este artigo analisa a influência do Poder Executivo sobre o ciclo financeiro e orçamentário das emendas parlamentares individuais. A participação dos Poderes Executivo e Legislativo no ciclo orçamentário da União tem sido alvo de vários debates e estudos empíricos na Ciência Política brasileira. Essas análises, em sua maioria, centraram-se em entender o papel das emendas orçamentárias individuais na construção de apoio legislativo à agenda do Poder Executivo. No centro desse debate, apresentam-se duas grandes interpretações: de um lado, encontram-se aqueles que apontam para o uso constante das emendas pelo Executivo enquanto uma moeda de troca capaz de mobilizar o apoio individual dos parlamentares à sua agenda (PEREIRA; RENNÓ, 2001; PEREIRA; MUELLER, 2002, 2003), e aqueles que fazem críticas ao argumento anterior, por acreditar que a liberação das emendas e o apoio à agenda do Executivo são construídos em bases partidárias (FIGUEIREDO; LIMONGI, 1999, 2002, 2005, 2008; MESQUITA, 2008; LUZ, 2016).

Apesar de divergirem em relação ao modelo de negociação em torno da agenda política do Executivo e, paralelamente, sobre a liberação das emendas orçamentárias individuais, ambas as interpretações partem da assertiva de que o Executivo possui a supremacia legal sobre a execução do orçamento da União. A participação do Poder Legislativo, nesse contexto, ficaria restrita apenas em alterar, por meio das emendas orçamentárias, o Projeto de Lei Orçamentária (PLO) enviado pelo Executivo para apreciação no Congresso Nacional. Isso significa dizer que mesmo após a aprovação do orçamento pelo Legislativo, o presidente da República, através dos Ministérios, não 
BONFIM, R. W. Leal; SANDES-FREITAS; V. E. V. de. Quem controla o orçamento? Apontamentos sobre o timing de liberação das emendas orçamentárias individuais. Caos - Revista Eletrônica de Ciências Sociais, João Pessoa, n. 23, p. 139 - 156, jul./dez. 2019. Disponível em: https://periodicos.ufpb.br/ojs2/index.php/caos/index.

precisa realizar os gastos aprovados, incluindo as emendas orçamentárias aprovadas pelos parlamentares. ${ }^{1}$

Conforme apontado anteriormente, as análises empíricas acerca da relação Executivo-Legislativo em torno do orçamento federal focaram apenas em compreender o perfil dos parlamentares e dos partidos políticos que têm suas emendas individuais executadas pelo Executivo e, consequentemente, como ocorre a construção do apoio legislativo a sua agenda durante as votações no Congresso Nacional. No entanto, nada se sabe sobre os mecanismos que permitem ao Executivo controlar o timing de liberação das emendas orçamentárias individuais. A partir disso, questiona-se: dado o formato do ordenamento financeiro e orçamentário brasileiro, ao qual as emendas orçamentárias individuais estão submetidas, como o Poder Executivo consegue influenciar o volume de recursos pagos referentes às emendas individuais solicitadas pelos deputados e senadores brasileiros na LOA? Partimos da assertiva de que o ciclo financeiro e orçamentário, que compreende as emendas individuais, caracteriza-se pelo seu alto grau de subordinação ao Poder Executivo. Dito de outra forma, o Poder Executivo é capaz de dissipar as preferências do Poder Legislativo no processo orçamentário alterando os valores das emendas individuais aprovadas na LOA em todos os estágios do ciclo financeiro e orçamentário, que vai desde a fase de empenho até o pagamento final.

A análise compreende dois períodos distintos. O primeiro (2012-2013), caracterizado pelo caráter autorizativo do orçamento, com a clara preponderância do Executivo sobre a execução das emendas individuais. E o segundo (2014-2017), marcado pela promulgação da PEC do orçamento impositivo, que torna obrigatória a execução, pelo Executivo, das emendas individuais aprovadas na LOA. Assim sendo, um dos objetivos deste artigo é realizar uma análise exploratória sobre as mudanças no orçamento estabelecida pela EC n ${ }^{\circ}$ 86/2015 (BRASIL,2015).

\footnotetext{
${ }^{1}$ Em fevereiro de 2015, foi promulgada a Emenda à Constituição (EC) do orçamento impositivo pelo Congresso Nacional. Em tese, essa EC garante a obrigatoriedade de execução, pelo Executivo, de todas as emendas individuais aprovadas pelos deputados federais e senadores na Lei Orçamentária Anual (LOA). Seu texto estabelece a obrigatoriedade de execução das emendas parlamentares individuais no máximo de até $1,2 \%$ da Receita Corrente Líquida (RCL) prevista no Projeto de Lei Orçamentária Anual (PLOA) encaminhado pelo Poder Executivo. Metade desses recursos deve ser destinado para a área de saúde. Vale ressaltar que a $\mathrm{EC} \mathrm{n}^{\circ} 86$ foi aprovada em 2015. Todavia, antes dessa mudança constitucional, o Congresso Nacional optou por incluir no orçamento de 2014, via Lei de Diretrizes Orçamentárias (LDO), a execução obrigatória das emendas.
} 
BONFIM, R. W. Leal; SANDES-FREITAS; V. E. V. de. Quem controla o orçamento? Apontamentos sobre o timing de liberação das emendas orçamentárias individuais. Caos - Revista Eletrônica de Ciências Sociais, João Pessoa, n. 23, p. 139 - 156, jul./dez. 2019. Disponível em: https://periodicos.ufpb.br/ojs2/index.php/caos/index.

Em relação aos dados utilizados neste trabalho, vale ressaltar que antes de 2014, não era possível identificar nas planilhas compiladas pelo Centro de Informação e Documentação da Câmara dos Deputados, a conexão entre o autor da emenda, seu partido e a funcional programática. ${ }^{2}$ Às vezes, uma mesma funcional agregava as programações referentes às emendas individuais e coletivas dos parlamentares junto com a proposta original do Projeto Lei Orçamentária (PLO) elaborada pelo Executivo. Assim, durante a fase de execução das programações, não era possível identificar se o recurso liberado era exclusivo das emendas orçamentárias ou da proposta do Executivo. ${ }^{3}$ Todavia, a partir de 2014, foi criado um identificador de resultado primário (RP 6) para acompanhar as emendas em todos os seus estágios orçamentários. Além disso, nos últimos anos a Consultoria de Orçamento e Fiscalização Financeira da Câmara dos Deputados (CONOF) vem buscando disponibilizar os dados orçamentários relacionados a programações exclusivas de emendas individuais para o período anterior a 2014. No entanto, os dados disponibilizados pelo CONOF, e necessários para a realização deste artigo, só estão disponíveis até o ano de 2012. Por esse motivo, justificamos nosso recorte temporal entre 2012 e 2017.4

Este trabalho encontra-se organizado em duas seções, além desta introdução e da conclusão. A primeira seção descreve os pilares do processo orçamentário brasileiro, erguidos a partir da Constituição de 1988, com enfoque nos dispositivos institucionais que garantem a preponderância da proposta orçamentária elaborada pelo poder Executivo, e no espaço reservado para as emendas parlamentares no orçamento da União. A segunda seção analisa os dados empíricos sobre emendas orçamentárias individuais aprovadas e executadas entre 2012 e 2017. Por fim, serão expostos os principais resultados deste trabalho.

\footnotetext{
${ }^{2}$ A funcional programática refere-se à classificação das despesas a partir da estrutura de programa, ação e subtítulo. Sua função é identificar a finalidade do gasto, isto é, identificar onde e em que os recursos serão alocados. Para mais detalhes, ver a portaria expedida pelo Ministério do Orçamento e Gestão de n $42 / 99$.

${ }^{3}$ Por exemplo, se a proposta do Poder Executivo para uma determinada funcional programática prevê um orçamento inicial de 200 mil, e essa mesma funcional recebe mais 200 mil em emenda de um deputado, a execução final será efetuada a partir do orçamento total da Funcional (400 mil), de forma que, em caso de execução parcial (ex. executou apenas 200 mil), não é possível identificar se o valor executado pertencia aos 200 mil da emenda parlamentar ou ao 200 mil do orçamento proposto pelo Poder Executivo.

${ }^{4}$ Para o período posterior a 2013, utilizamos também os dados disponibilizados pelo Sistema Integrado de Administração Financeira do Governo Federal (SIAFI) e pelo Siga Brasil (Senado Federal).
} 
BONFIM, R. W. Leal; SANDES-FREITAS; V. E. V. de. Quem controla o orçamento? Apontamentos sobre o timing de liberação das emendas orçamentárias individuais. Caos - Revista Eletrônica de Ciências Sociais, João Pessoa, n. 23, p. 139 - 156, jul./dez. 2019. Disponível em: https://periodicos.ufpb.br/ojs2/index.php/caos/index.

\section{Construindo o Orçamento Federal: onde estão as emendas orçamentarias individuais?}

O processo de construção do orçamento no Brasil vem sofrendo modificações ao longo dos anos, apresentando situações em que ora o Legislativo define a forma como os recursos públicos serão distribuídos (República de 1946), ora o domínio da agenda orçamentária se encontra centralizada nas mãos do Executivo (Regime Militar). No período pós-redemocratização, foram criados novos dispositivos constitucionais que garantiram a participação de ambos os Poderes na elaboração do orçamento da União. Esse modelo introduziu novas formas de interação na relação Executivo-Legislativo em nível federal (FIGUEIREDO; LIMONGI, 2008).

Atualmente, o orçamento é composto por três instrumentos que garantem a regulamentação, participação e distribuição dos recursos públicos da União. O primeiro diz respeito ao Plano Plurianual - PPA. Nessa fase, o Presidente da República deve estabelecer as prioridades do governo para um período de quatro anos. Sua elaboração é feita a partir dos gastos indicados por cada Ministério à Secretaria de Orçamento Fiscal (SOF). É nessa fase que são estabelecidas as principais metas e diretrizes de médio e longo prazos do governo federal.

A segunda fase do processo orçamentário da União é a formulação da Lei de Diretrizes Orçamentárias - LDO. Nessa etapa serão estabelecidas as principais metas e prioridades do governo federal para o exercício financeiro subsequente. É função da LDO ajustar e orientar as ações do governo seguindo as reais viabilidades de caixa do Tesouro Nacional. Além disso, ela deve ser compatível com o PPA.

É partir da LDO que a Lei Orçamentária Anual (LOA) é elaborada. Nesse momento, o governo define as principais metas compreendidas no PPA que deverão ser alcançadas naquele ano. Após a fase de elaboração, a LOA é submetida ao Poder Legislativo para discussão, votação e aprovação. Inicialmente a lei orçamentária é apreciada através da Comissão Mista do Orçamento (CMO). Esse órgão colegiado é formado por parlamentares das duas casas legislativas. ${ }^{5}$ Suas funções se estendem desde

\footnotetext{
${ }^{5}$ Essa comissão é composta por 30 deputados federais e 10 senadores. Cada parlamentar possui um suplente. O parecer da Comissão é levado para votação no Plenário. Para tanto, a sessão legislativa deve ser presidida por membros das duas Casas do Congresso Nacional (art. $5^{\circ}$ Res. 01/2006-CN).
} 
BONFIM, R. W. Leal; SANDES-FREITAS; V. E. V. de. Quem controla o orçamento? Apontamentos sobre o timing de liberação das emendas orçamentárias individuais. Caos - Revista Eletrônica de Ciências Sociais, João Pessoa, n. 23, p. 139 - 156, jul./dez. 2019. Disponível em: https://periodicos.ufpb.br/ojs2/index.php/caos/index.

a análise de leis orçamentárias e projetos de créditos adicionais até a análise das contas do Presidente da República.

Durante a apreciação do orçamento no Congresso, a CMO elabora quatro diferentes pareceres: parecer de receita, o parecer preliminar, os pareceres setoriais e o parecer final. O parecer de receita tem como objetivo analisar a estimativa de receita, no qual também estão contidas as emendas. O parecer preliminar, de autoria do Relator Geral, além de analisar a estimativa de receita, contém os recursos disponíveis para as relatorias setoriais e para o acolhimento das emendas individuais. Os pareceres setoriais contêm o posicionamento dos relatores setoriais acerca da proposta dos órgãos que fazem parte da área temática e das emendas relacionadas a esta área. Por fim, o parecer final também de responsabilidade do Relator Geral - tem como objetivo consolidar os pareceres setoriais e os acordos estabelecidos com as bancadas. A partir disso, o parecer é encaminhado ao Plenário do Congresso Nacional.

FIGURA 1 - Ciclo integrado de planejamento e orçamento brasileiro pós-1988

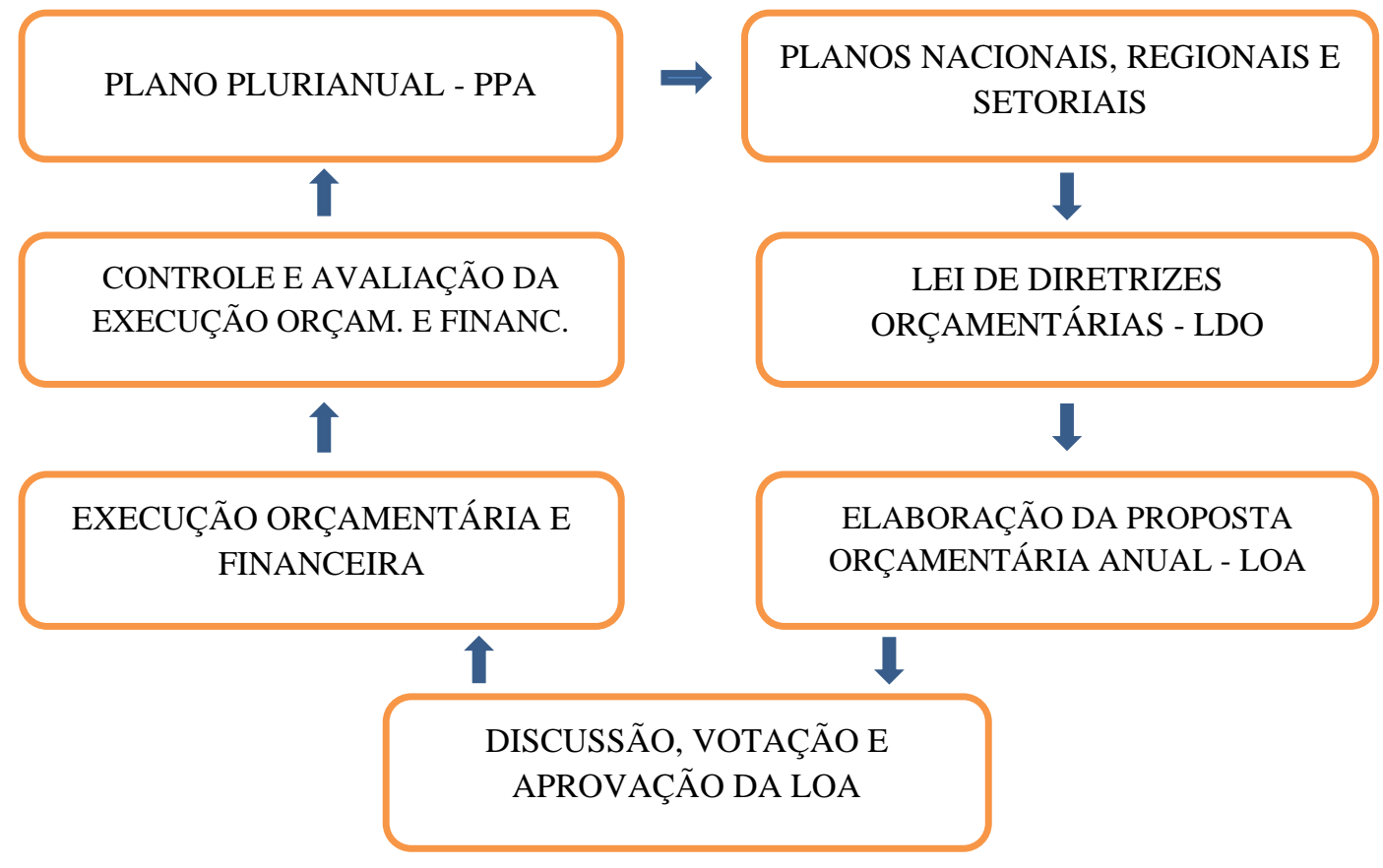

Fonte: Câmara dos Deputados. Disponível em: https://www2.camara.leg.br/orcamento-dauniao/cidadao/entenda/cursopo/planejamento.html 
BONFIM, R. W. Leal; SANDES-FREITAS; V. E. V. de. Quem controla o orçamento? Apontamentos sobre o timing de liberação das emendas orçamentárias individuais. Caos - Revista Eletrônica de Ciências Sociais, João Pessoa, n. 23, p. 139 - 156, jul./dez. 2019. Disponível em: https://periodicos.ufpb.br/ojs2/index.php/caos/index.

Os três instrumentos de construção do orçamento federal, citados anteriormente, garantem ao Poder Executivo a prerrogativa exclusiva sobre toda e qualquer legislação ligada a matérias orçamentárias. A Constituição Federal de 1988 permitiu também a participação do Congresso Nacional no processo orçamentário. Entretanto, a atuação dos parlamentares que não fazem parte dos órgãos colegiados presentes durante o processo de apreciação da LOA se dá de forma bastante limitada, restringindo-se à apresentação de emendas individuais e coletivas.

A emenda parlamentar pode ser definida enquanto um dispositivo institucional, utilizado pelo Poder Legislativo para propor alterações no Projeto de Lei Orçamentária Anual (PLOA) enviado pelo Executivo. Essas modificações podem ser realizadas através de acréscimo, anulação e modificação de itens do PLOA. ${ }^{6}$ No que se refere à apresentação de emendas orçamentárias pelos membros do legislativo, estas seguem um conjunto de restrições estabelecidas por normas constitucionais. A Constituição Federal de 1988, em seu artigo 166, define que apenas serão aceitas as emendas que seguirem os seguintes critérios:

Indiquem os recursos necessários, admitidos apenas os provenientes de anulação de despesa, excluídas as que indicam sobre: a) dotações para pessoal e seus encargos; b) serviço da dívida; c) transferências tributárias constitucionais para estados, municípios e Distrito Federal (BRASIL, 1988).

No que diz respeito aos grupos de despesas no orçamento (GND), a CF/1988 limitou a ação dos membros do legislativo - parlamentares, bancadas estaduais e comissões - apenas aos gastos relacionados com investimentos. Isto quer dizer que os membros do legislativo não têm acesso à maior parte dos recursos orçamentários da União. O gráfico 1 apresenta os valores autorizados na LOA para cada grupo de despesa (GND).

É possível observar que as despesas referentes ao grupo de investimentos apresentam uma das menores taxas de recursos autorizados na LOA. Se levarmos em conta somente o período referente à vigência da $\mathrm{EC} \mathrm{n}^{\circ} 86 / 2015$, os valores aprovados nesse grupo de despesa é o que apresenta o menor percentual entre todos os grupos da despesa pública. Além disso, a média de recursos autorizados no GND de investimentos

\footnotetext{
${ }^{6}$ As emendas podem ser de três tipos: (1) à despesa - indica a inclusão, remanejamento ou cancelamento de dotações; (2) à receita - propõe a inclusão, exclusão ou alteração de receitas em casos de erros; e (3) ao texto - alteram o texto do projeto de lei.
} 
BONFIM, R. W. Leal; SANDES-FREITAS; V. E. V. de. Quem controla o orçamento? Apontamentos sobre o timing de liberação das emendas orçamentárias individuais. Caos - Revista Eletrônica de Ciências Sociais, João Pessoa, n. 23, p. 139 - 156, jul./dez. 2019. Disponível em: https://periodicos.ufpb.br/ojs2/index.php/caos/index.

nesse período, é inferior aos valores aprovados no período anterior às mudanças da EC do orçamento impositivo. Em termos gerais, o governo federal tem direcionado menos recursos para esse grupo após a vigência da EC do orçamento impositivo. Além disso, quando olhamos para os valores pagos em relação ao que é aprovado, este grupo possui a menor proporção de pagamento durante todo o recorte temporal (ver gráfico 2).

Gráfico 1 - Percentual de recursos autorizados na LOA por grupos de despesa (20122017)

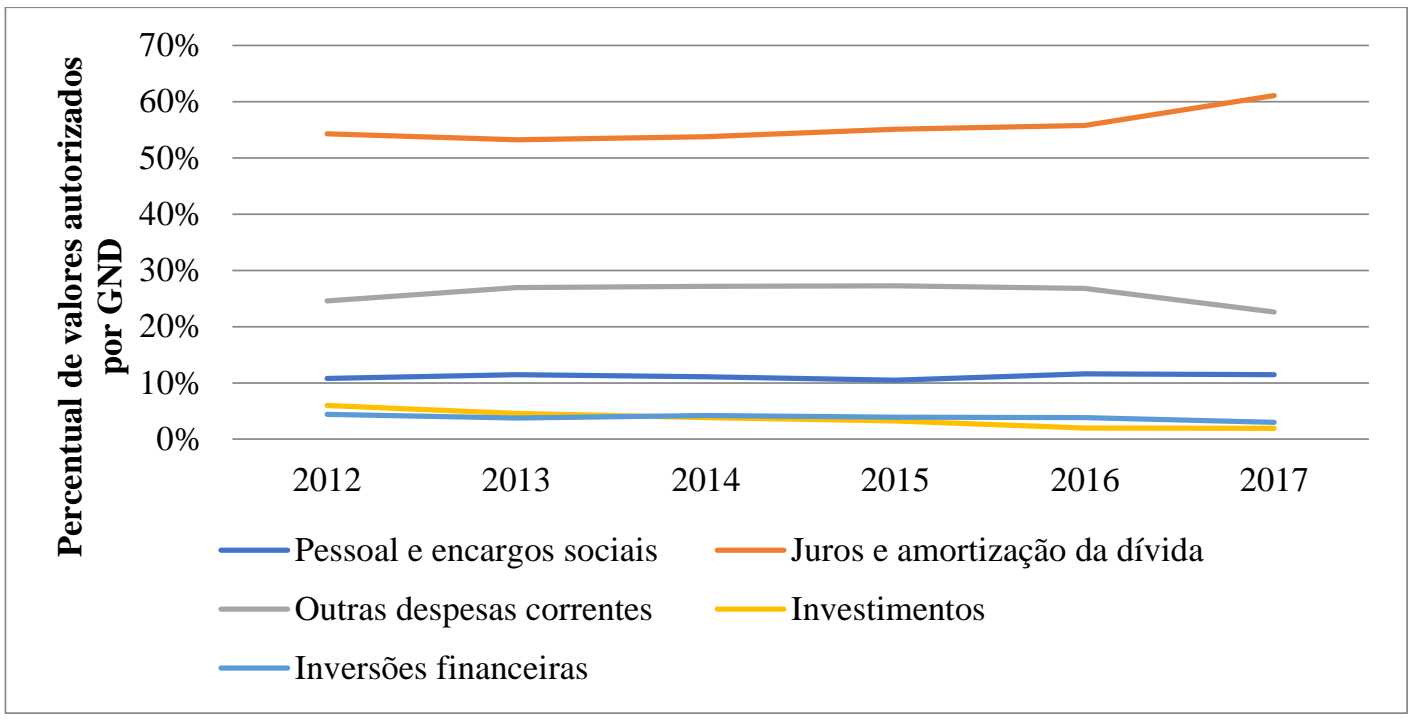

Fonte: Elaboração dos autores a partir dos dados do CONOF

Gráfico 2 - Percentual de valores pagos por grupo de despesa (2012-2017)

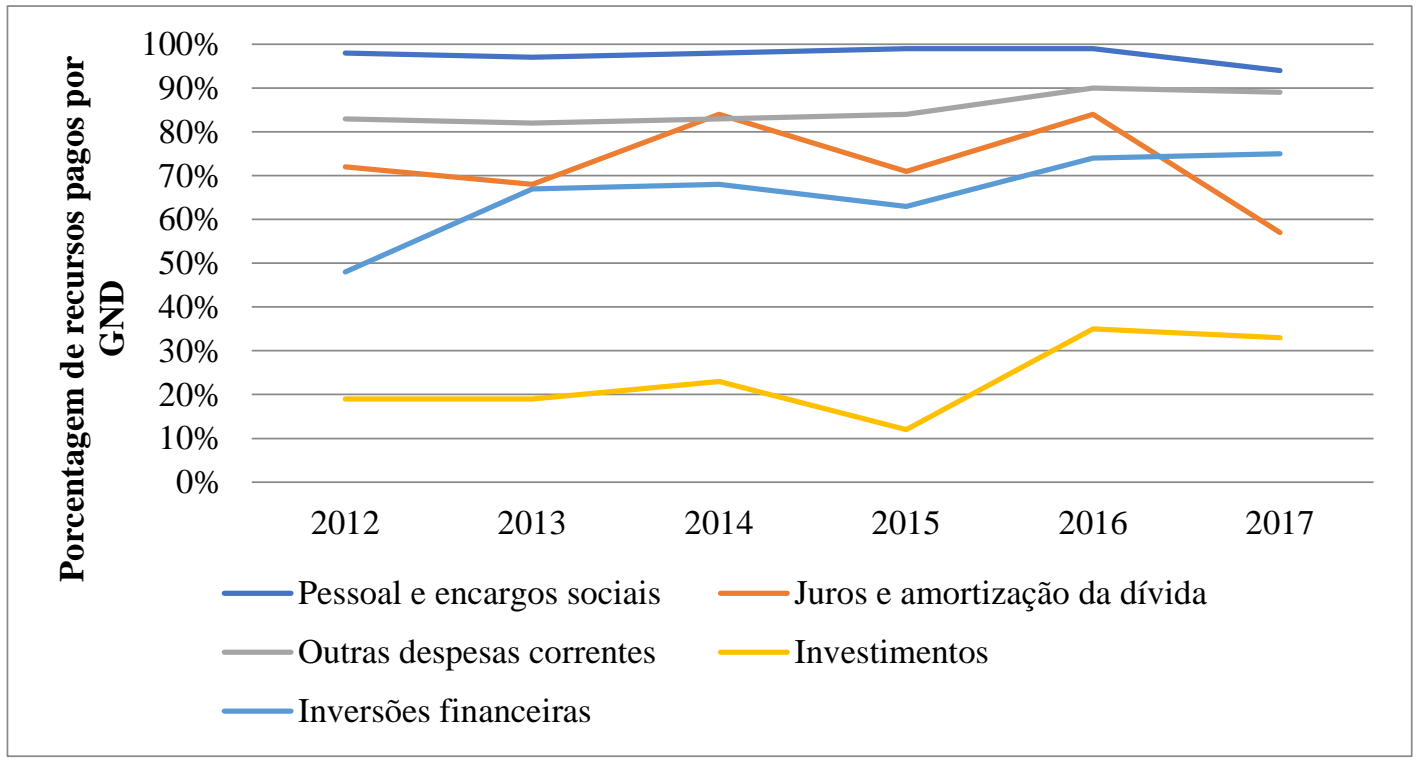

Fonte: Elaboração dos autores a partir dos dados do CONOF 
BONFIM, R. W. Leal; SANDES-FREITAS; V. E. V. de. Quem controla o orçamento? Apontamentos sobre o timing de liberação das emendas orçamentárias individuais. Caos - Revista Eletrônica de Ciências Sociais, João Pessoa, n. 23, p. 139 - 156, jul./dez. 2019. Disponível em: https://periodicos.ufpb.br/ojs2/index.php/caos/index.

De acordo com o gráfico 2, podemos observar que os valores pagos em torno do grupo de investimentos - no qual os membros do legislativo podem inserir suas emendas - sempre foram inferiores aos valores totais autorizados. Ainda que os valores pagos tenham aumentado no período posterior à aprovação da EC nº6/2015, estes nunca ultrapassam os $35 \%$ do que de fato é aprovado. Isto significa que, entre todos os grupos de despesa do orçamento, o que tem menos recursos pagos pelo Executivo é aquele que engloba as emendas individuais. Esse padrão pode ser observado antes e após a vigência das mudanças no orçamento. Se as emendas são, de fato, utilizadas como moeda de troca, é possível supor que os parlamentares assumem um risco muito elevado. Levando em conta o baixo nível de execução das despesas em investimento, nada garante que as emendas serão liberadas pelo Executivo.

Em síntese, a CF/88 garantiu ao Poder Executivo a prerrogativa exclusiva sobre toda e qualquer legislação ligada a matérias orçamentárias. O novo texto constitucional ainda assegurou ao Poder Legislativo a participação no orçamento federal, garantindolhe o direito de alterar a proposta orçamentária enviada pelo Executivo. No que se refere à participação dos parlamentares no processo orçamentário, este segue um conjunto de restrições estabelecidas por normas constitucionais que limitam sua ação individual. ${ }^{7}$ Além disso, as emendas orçamentárias representam uma pequena parcela das despesas do governo, ocupando um pequeno espaço no interior do orçamento da União.

\section{Emendas Parlamentares Individuais no Ordenamento Orçamentário Brasileiro}

É consenso na literatura que o Executivo possui o domínio legal sobre o orçamento e, consequentemente, sobre a liberação das emendas orçamentárias. No entanto, a literatura ainda não explorou quais mecanismos do orçamento permitem ao Executivo controlar o timing e o volume de liberação desses recursos. Esta seção busca explorar essa lacuna. Para tanto, foram analisadas todas as emendas orçamentárias individuais dos deputados e senadores brasileiros aprovadas e executadas entre 2012 e 2017. Parte do recorte temporal compreende os quatro anos iniciais de vigência da EC do orçamento impositivo. A EC n86/2015 tornou obrigatória à execução orçamentária e

\footnotetext{
${ }^{7}$ Outro ponto que merece destaque é o fato de que as emendas não podem ser alocadas para programas específicos de interesse dos parlamentares. Elas devem ser introduzidas em programas previamente definidos pelo Executivo no Plano Plurianual (PPA) e na LDO, buscando cumprir os objetivos já traçados nesses programas.
} 
financeira das receitas decorrentes das emendas individuais. Essas mudanças atingem somente as emendas orçamentárias individuais. As regras de execução das outras despesas do orçamento mantiveram-se inalteradas, seguindo as disposições estabelecidas pela $\mathrm{CF} / 88$. A seguir, serão apontadas as principais fases do ciclo orçamentário e financeiro das emendas individuais, bem como os mecanismos que permitem ao Executivo interferir nesse processo.

\subsection{Análise dos dados}

A influência do poder Executivo sobre a execução das emendas parlamentares individuais pode ser observada a partir da relação entre as emendas que são aprovadas na LOA, que seguem o interesse do Poder Legislativo, e os valores que podem sofrer interferência do Poder Executivo, tais como os valores empenhados e pagos. Essas mudanças podem ser observadas no interior dos estágios do ordenamento financeiro e orçamentário brasileiro, no qual as emendas individuais estão submetidas. Após a aprovação da LOA, a execução da emenda é empreendida a partir do cumprimento de três etapas: empenho, liquidação e pagamento.

O empenho é o primeiro estágio da despesa pública, e consiste no ato que cria para o Estado a obrigação de pagamento pendente. Para que o empenho seja efetivado, basta que o prestador de serviços atenda todos os critérios legais de autorização do pagamento. A liquidação consiste na verificação do serviço prestado pelo credor. Nessa fase, a obra, mesmo que já tenha sido executada, encontra-se em processo de análise e conferência. $\mathrm{O}$ pagamento é a terceira fase da despesa e consiste no pagamento da obra executada, resultando na extinção da obrigação. Quando o pagamento não é realizado no exercício correspondente, o ele será inscrito nos restos a pagar. Os restos a $\operatorname{pagar}^{8}$ constituem obrigações financeiras que compõem a dívida referente às despesas empenhadas, porém, não pagas e não canceladas até o dia 31 de dezembro.

Os dados do gráfico abaixo apontam que valores solicitados pelo Legislativo para as emendas individuais sofrem restrições em todas as etapas do seu ciclo financeiro e

\footnotetext{
${ }^{8}$ Estes se dividem em duas categorias: (1) restos a pagar processados; e (2) restos a pagar não processados. A primeira categoria refere-se às despesas empenhadas cuja liquidação já ocorreu. A segunda diz respeitos às despesas empenhadas que não foram liquidadas e nem pagas até 31 de dezembro.
} 
BONFIM, R. W. Leal; SANDES-FREITAS; V. E. V. de. Quem controla o orçamento? Apontamentos sobre o timing de liberação das emendas orçamentárias individuais. Caos - Revista Eletrônica de Ciências Sociais, João Pessoa, n. 23, p. 139 - 156, jul./dez. 2019. Disponível em: https://periodicos.ufpb.br/ojs2/index.php/caos/index.

orçamentário. ${ }^{9}$ É possível observar que, com exceção do ano de 2015, os valores empenhados após a vigência da EC n ${ }^{\circ} 86 / 2015$ foram os maiores da série histórica. Em relação aos valores pagos, estes se mantiveram baixos até 2014, representando menos de $30 \%$ dos valores solicitados para cada ano. No entanto, a partir de 2015 esses valores aumentam de maneira significativa, atingindo seu valor máximo em 2016. Ainda que esses valores tenham aumentado, eles nunca ultrapassaram os $55 \%$ dos valores solicitados. Podemos observar que, em cada fase do orçamento, o Executivo altera os valores liberados, distanciando-se da proposta original enviada pelo Legislativo. Esse padrão é observado em toda a série histórica.

Gráfico 3 - Porcentagem de emendas individuais empenhadas e pagas (incluindo restos a pagar) em relação ao que é solicitado pelo Congresso Nacional (2012-2017)

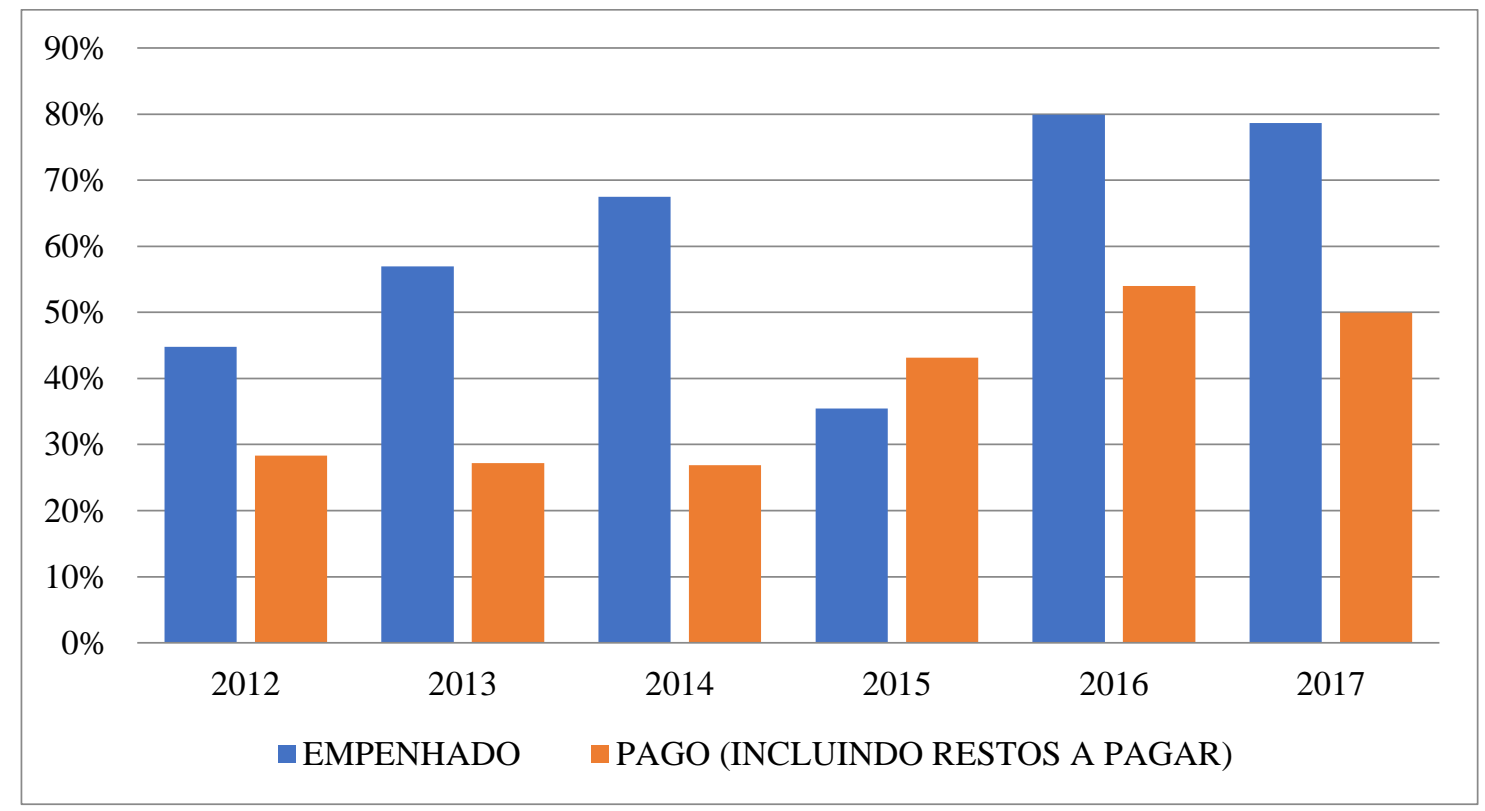

Fonte: Elaboração dos autores a partir dos dados do CONOF e do SIGA

Apesar do aumento dos recursos para emendas individuais a partir da EC $\mathrm{n}^{\circ} 86 / 2015$, as taxas de pagamento das emendas mantiveram-se baixas em quase toda a série histórica. Entretanto, a partir de 2015 esses valores crescem de maneira significativa. Este aumento pode ter relação com as mudanças nas regras de execução das emendas individuais. Uma das principais mudanças estabelecidas pela $\mathrm{EC} \mathrm{n}^{\circ} 86 / 2015$ diz respeito ao contingenciamento de despesas: o contingenciamento das emendas passou a ser

\footnotetext{
${ }^{9}$ Não foi possível ter acesso aos dados referentes aos valores liquidados. Por esse motivo, optamos em analisar somente os valores empenhados e pagos (incluindo restos a pagar).
} 
BONFIM, R. W. Leal; SANDES-FREITAS; V. E. V. de. Quem controla o orçamento? Apontamentos sobre o timing de liberação das emendas orçamentárias individuais. Caos - Revista Eletrônica de Ciências Sociais, João Pessoa, n. 23, p. 139 - 156, jul./dez. 2019. Disponível em: https://periodicos.ufpb.br/ojs2/index.php/caos/index.

proporcional às outras despesas discricionárias do governo federal. Nos anos anteriores às mudanças no orçamento, as emendas orçamentárias (individuais e coletivas) contingenciadas representavam quase todo o valor total da despesa contingenciada pelo Executivo.

Gráfico 4 - Contingenciamento total do orçamento x emendas contingenciadas (20122017)

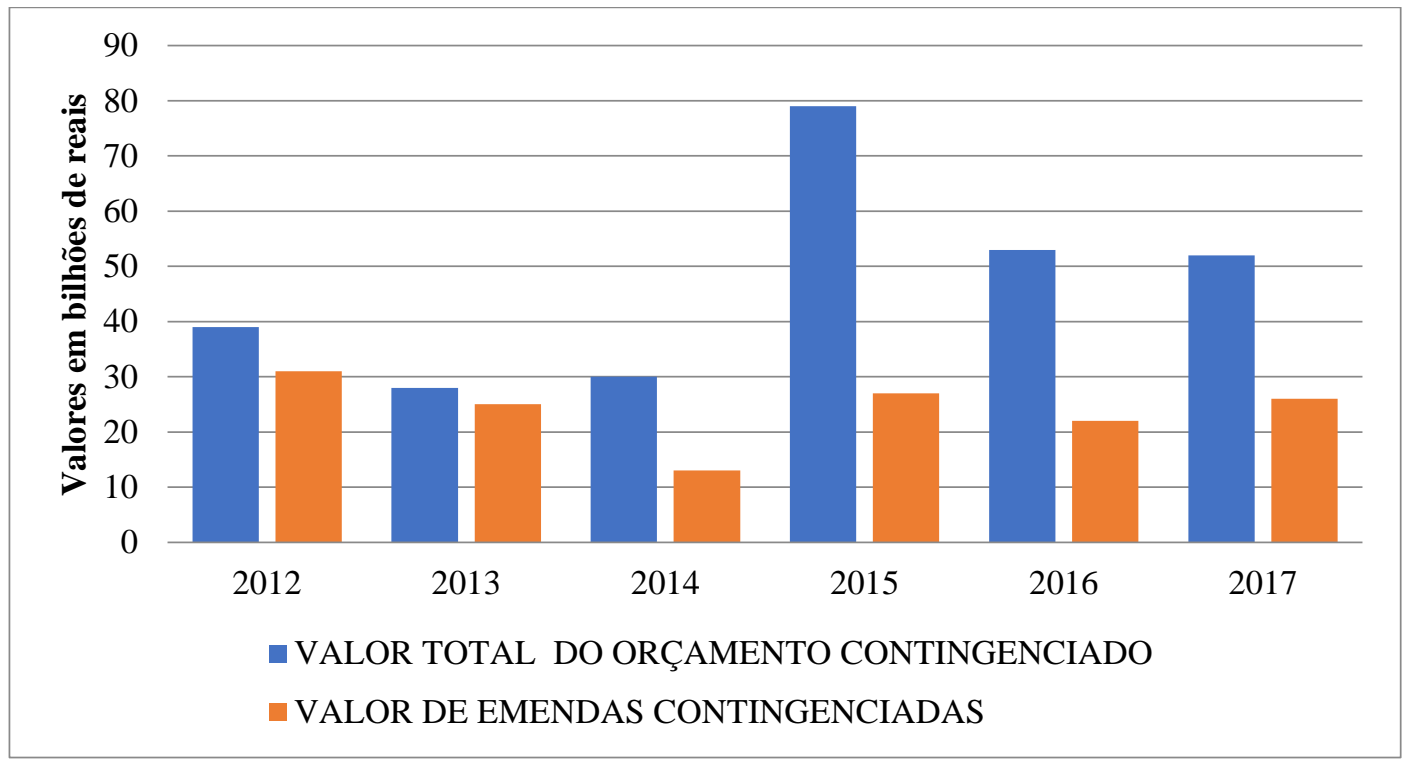

Fonte: Elaboração dos autores a partir dos dados do CONOF

De acordo com o gráfico acima, podemos observar que, a partir de 2014, os valores referentes ao contingenciamento das emendas caíram drasticamente em relação ao orçamento total contingenciado. Em 2014, por exemplo, os valores solicitados por meio das emendas somaram R\$ 19,8 bilhões. No entanto, R\$ 13,3 bilhões foram contingenciados pelo Poder Executivo. Isso quer dizer que R\$ 6,5 bilhões ficaram protegidos da tesoura do Executivo. Nesse mesmo ano, foi solicitado em torno de $\mathrm{R} \$$ 8,671 bilhões para as emendas individuais. Levando em conta as mudanças nas regras do orçamento, os deputados e senadores brasileiros teriam direito ao montante de 1,2\% da RCL do ano de 2013. Esse valor representa um total de $\mathrm{R} \$ 7,8$ bilhões. Todavia, devido ao decreto de contingenciamento $\mathrm{n}^{\circ} 8.197$ de 2014, esses valores foram reduzidos na mesma proporção das outras despesas discricionárias, representando uma perda de $15,5 \%$ do valor fixado naquele ano para as emendas individuais. No final desse processo, o 
BONFIM, R. W. Leal; SANDES-FREITAS; V. E. V. de. Quem controla o orçamento? Apontamentos sobre o timing de liberação das emendas orçamentárias individuais. Caos - Revista Eletrônica de Ciências Sociais, João Pessoa, n. 23, p. 139 - 156, jul./dez. 2019. Disponível em: https://periodicos.ufpb.br/ojs2/index.php/caos/index.

Executivo liberou para empenho, o valor de $\mathrm{R}$ \$ 6,4 bilhões para as emendas individuais, representando uma perda de $25,7 \%$ do valor inicialmente solicitado ${ }^{10}$.

Além disso, a Emenda Constitucional n86/2015 estabeleceu que as emendas individuais só devem deixar de ser executadas em casos de impedimentos técnicos legais. No que se refere aos impedimentos, fica a cargo dos órgãos de fiscalização definir os critérios e parâmetros de execução das emendas individuais. ${ }^{11}$

Gráfico 5 - Emendas com problemas técnicos $(2014-2017)^{12}$

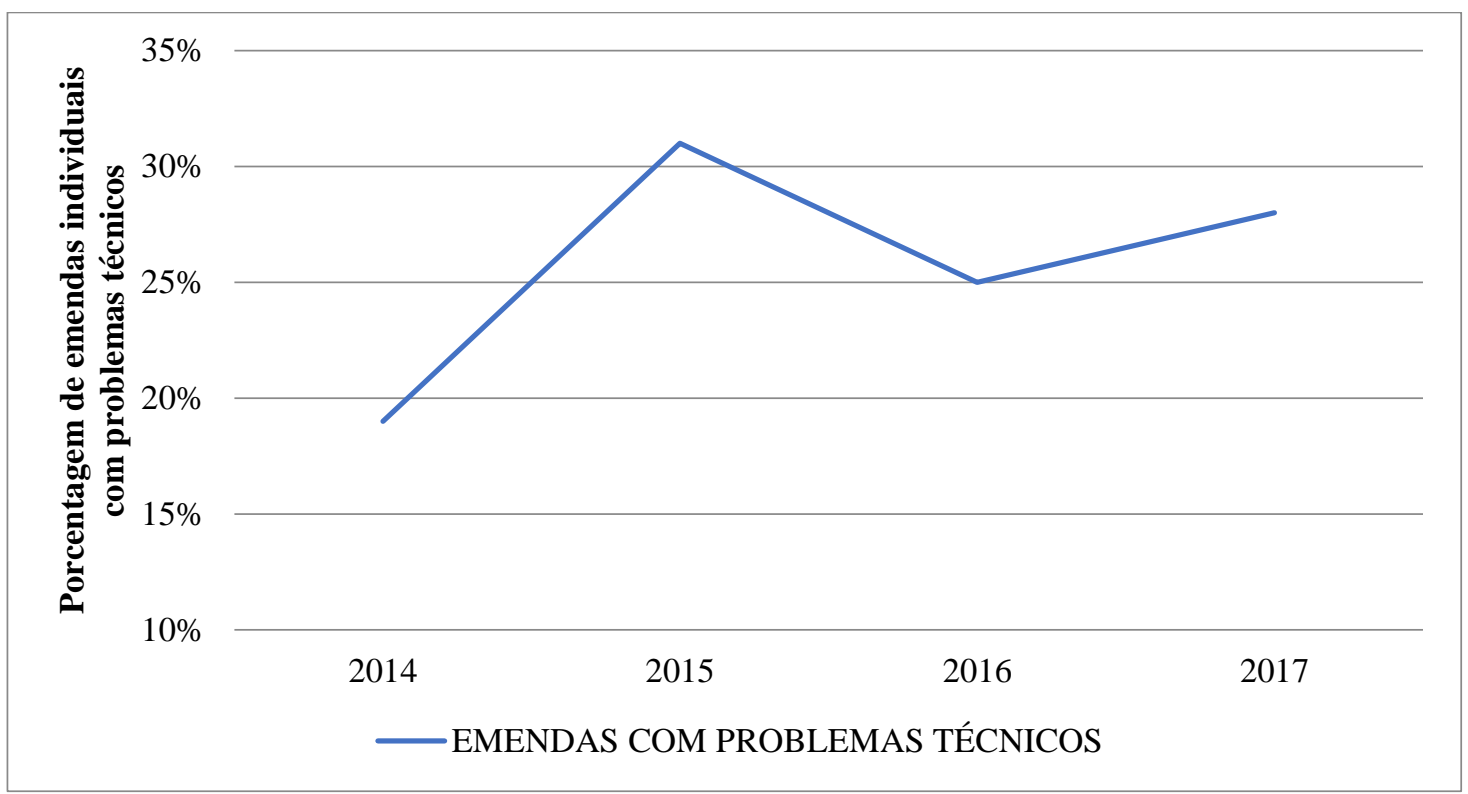

Fonte: Elaboração dos autores a partir dos dados do CONOF

O gráfico acima aponta que, nos quatro primeiros anos de vigência do orçamento impositivas, em torno de $\mathrm{R} \$ 9,5$ bilhões em recursos destinados por meio de emendas individuais apresentaram algum problema de ordem técnica. Essa quantia representa $26 \%$

\footnotetext{
${ }^{10}$ Para mais informações, ver Volpe (2019) e Volpe; Cambraia (2015).

${ }^{11}$ De acordo com o art. 52, § 2 , I, da LDO/2014, "fica a cargo dos Poderes, do Ministério Público da União (MPU) e a Defensoria Pública da União (DPU), no prazo de 120 dias da publicação da lei orçamentária, verificar os impedimentos para execução das programações decorrentes de emendas individuais, bem como informar as justificativas ao Congresso Nacional". Cabe destacar também que a Instrução Normativa ${ }^{\circ} 1$, de 2014, da Comissão Mista de Planos, Orçamentos Públicos e Fiscalização (CMO) permitiu aos parlamentares indicar medidas corretivas ou necessárias para execução das respectivas dotações bloqueadas. Essas indicações devem estar de acordo com as disposições do inciso II do $\S 14$ do art. 166 da Constituição Federal. Em suma, a maioria dos casos de impedimentos pode ser sanada por meio de medidas administrativas, decretos para remanejamento de programação e alterações de modalidade e grupo natureza de despesa.

${ }^{12}$ Os dados anteriores a 2014 não estão disponíveis.
} 
BONFIM, R. W. Leal; SANDES-FREITAS; V. E. V. de. Quem controla o orçamento? Apontamentos sobre o timing de liberação das emendas orçamentárias individuais. Caos - Revista Eletrônica de Ciências Sociais, João Pessoa, n. 23, p. 139 - 156, jul./dez. 2019. Disponível em: https://periodicos.ufpb.br/ojs2/index.php/caos/index.

do valor total das emendas individuais solicitados na LOA neste período. ${ }^{13}$ Ainda que os valores pagos tenham aumentado em relação ao período anterior à aprovação da EC, isto não quer dizer que eles estejam sendo liberados em sua totalidade. Diniz (2016) afirma que o Executivo não permitiu que o Congresso Nacional determinasse conceitualmente o que representava um impedimento técnico, pois os dispositivos relativos ao assunto na LDO de 2015 foram vetados pela então presidente da República, Dilma Rousseff.

A partir disso, dois pontos merecem destaque. O primeiro é que mesmo tendo atingido valores recordes em empenho a partir de 2014, estes, ainda assim, ficaram abaixo do valor obrigatório definido na Emenda Constitucional $\mathrm{n}^{\circ} 86$. O instrumento do contingenciamento e a exclusão das emendas com problemas de ordem técnica garantem ao Executivo uma janela de oportunidade para alterar os valores solicitados pelos parlamentares para as emendas individuais durante a primeira fase de seu ciclo financeiro. O segundo ponto refere-se aos valores pagos. Esses valores tendem a ser divididos em dois grupos em um mesmo exercício financeiro: 1) valores pagos; emendas individuais pagas no exercício financeiro em que estas são empenhadas, e 2) os restos a pagar pagos; valores de emendas individuais empenhados em anos anteriores e que são pagos em exercícios financeiros posteriores. Como veremos mais a seguir, a maior parte dos valores pagos durante o ano do empenho das emendas é referente a restos a pagar de anos anteriores.

Apesar de garantir a obrigatoriedade de execução das emendas, a EC do orçamento impositivo estabeleceu que parte do pagamento referente às emendas poderia ser realizada no limite de até $0,6 \%$ da RCL em "restos a pagar" de despesas anteriores. ${ }^{14}$ Os restos a pagar constituem obrigações financeiras que compõem a dívida referente às despesas empenhadas, porém não pagas e não canceladas até o dia 31 de dezembro. Quando a despesa pública não é paga no seu ano orçamentário correspondente, ela entra na ordem de pagamento da LOA do ano seguinte. Na prática, este dispositivo garante ao Executivo utilizar os recursos de emendas empenhadas em anos anteriores para cumprir

\footnotetext{
${ }^{13}$ Entre 2014 e 2017 foram solicitados na LOA, R\$ 36,547 bilhões em emendas individuais de deputados e senadores.

${ }^{14}$ De acordo com art. 166, $\S 16$, “os restos a pagar poderão ser considerados para fins de cumprimento da execução financeira prevista no $\S 11$ deste artigo, até o limite de $0,6 \%$ (seis décimos por cento) da receita corrente líquida realizada no exercício anterior".
} 
BONFIM, R. W. Leal; SANDES-FREITAS; V. E. V. de. Quem controla o orçamento? Apontamentos sobre o timing de liberação das emendas orçamentárias individuais. Caos - Revista Eletrônica de Ciências Sociais, João Pessoa, n. 23, p. 139 - 156, jul./dez. 2019. Disponível em: https://periodicos.ufpb.br/ojs2/index.php/caos/index.

os gastos obrigatórios de execução em um determinado ano. O gráfico abaixo (gráfico 6) apresenta os dados referentes aos restos a pagar entre 2012 e 2017.

Gráfico 6 - Percentual de valores pagos e restos a pagar de emendas individuais (20122017)

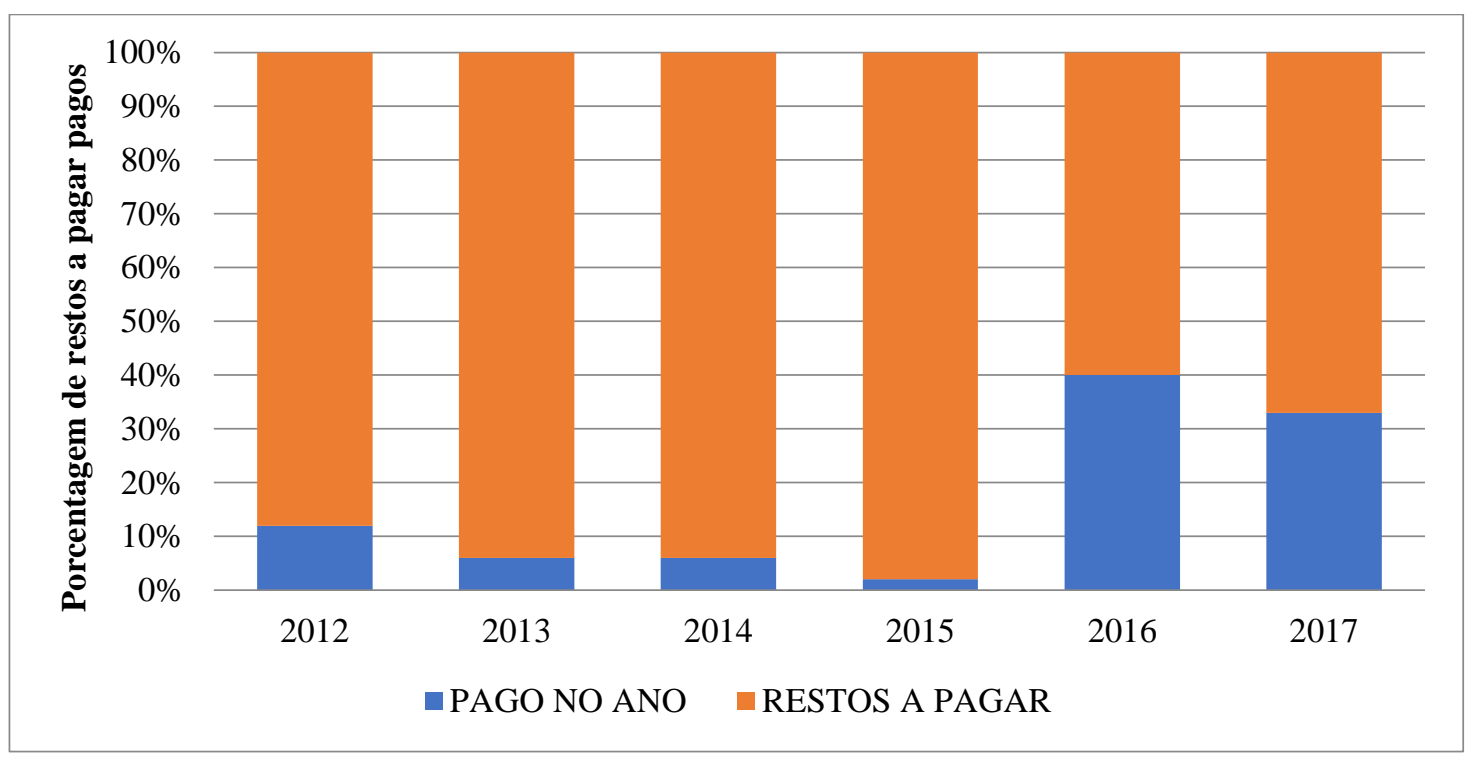

Fonte: Elaboração dos autores a partir dos dados do SIAFI, SIGA e CONOF

Podemos observar que os restos a pagar têm representado a maior parte dos valores pagos. Isto quer dizer que, em alguns casos, quando a emenda é de fato paga, o parlamentar que a propôs pode já não estar mais no exercício do cargo. Por exemplo, o valor total de emendas pagas (incluindo restos a pagar) em 2014 foi de R $\$ 2,36$ bilhões. Deste total, apenas $6 \%$ do valor foi pago no ano orçamentário de empenho das emendas. O resto do valor é referente a restos a pagar de emendas empenhadas em anos anteriores e que só foram pagas em 2014. ${ }^{15}$ Mesmo no ano de 2016, quando houve o maior percentual de valor pago no ano, os restos a pagar representaram em torno de $60 \%$ do valor total. Assim, quando olhamos para o timing do pagamento das emendas individuais, é possível afirmar que elas não são liberadas paralelamente às votações no Congresso Nacional. O motivo é simples: a maior parte dos recursos aprovados em um ano é

15 De acordo com os dados do CONOF, em relação ao valor total pago, $0,8 \%$ é referente a valores empenhados entre 2002 e 2008; 2,5\% é referente a 2009; 4,3\% é referente a 2010; $9 \%$ é referente a 2011; $27,7 \%$ é referente a 2012; 49,7\% é referente a 2013 (Fonte: adaptado a partir dos relatórios do CONOF). 
executada ao longo dos anos seguintes. ${ }^{16}$ Esse padrão é observado em toda a série histórica.

Mesmo com as mudanças nas regras de execução das emendas individuais propostas pelos parlamentares brasileiros e, por seguinte, o aumento dos recursos liberados para as emendas na LOA, grande parte dos valores pagos, ainda assim, é referente a despesas não executadas de anos anteriores. Mais que isso, a forma como esses recursos são liberados continua sendo uma prerrogativa exclusiva do Poder Executivo. Este agente, por meio dos dispositivos institucionais do orçamento, continua definindo quando e como as emendas serão executadas.

\section{Conclusão}

Este artigo buscou apontar que o domínio do Executivo sobre a liberação das emendas individuais dos deputados e senadores brasileiros é mais complexa do que é ocasionalmente apontado pela literatura. O Executivo consegue ter o domínio sobre as emendas individuais em todas as etapas do seu ciclo financeiro e orçamentário. Seu controle não se restringe apenas ao montante final de recursos liberados. Alguns instrumentos institucionais, como o contingenciamento de despesas, a exclusão de emendas com problemas técnicos e a inscrição dos restos a pagar, garantem a esse agente institucional o controle sobre as emendas orçamentárias desde a liberação dos valores inicialmente autorizados na LOA até o seu pagamento final. Mesmo com a EC n86/2015, que torna obrigatória a execução das emendas, o Executivo consegue contornar as preferências do Legislativo. Dado o formato do ciclo orçamentário e financeiro brasileiro e, consequentemente, as fases do orçamento aos quais as emendas individuais estão submetidas, podemos afirmar que em cada uma dessas fases, o Executivo consegue impor uma nova rodada de negociações frente ao Legislativo.

Por fim, ressaltamos que ao analisar o ciclo financeiro e orçamentário que compreende as emendas individuais, este artigo buscou também fornecer contribuições metodológicas. A literatura que estuda a relação entre execução de emendas individuais e apoio à agenda do Executivo não esclarece, em alguns casos, qual fase do orçamento

\footnotetext{
${ }^{16}$ Se levarmos em conta somente o período referente ao orçamento autorizativo (2012-2013), a média de emendas pagas no ano do empenho representa $10 \%$ do valor total.
} 
BONFIM, R. W. Leal; SANDES-FREITAS; V. E. V. de. Quem controla o orçamento? Apontamentos sobre o timing de liberação das emendas orçamentárias individuais. Caos - Revista Eletrônica de Ciências Sociais, João Pessoa, n. 23, p. 139 - 156, jul./dez. 2019. Disponível em: https://periodicos.ufpb.br/ojs2/index.php/caos/index.

está sendo considerada durante a análise. Esses estudos tendem a tratar a execução das emendas como um processo de fase única, no qual o Executivo define quais partidos e parlamentares serão beneficiados. Entretanto, conforme apontamos na seção anterior, os valores liberados para emendas tendem a variar de uma fase para outra do orçamento. Isso significa dizer que, dependendo da fase analisada, diferentes resultados podem ser alcançados. Com isso, esperamos que este trabalho possa auxiliar pesquisas futuras, que busquem compreender de modo mais detalhado como o processo orçamentário é capaz de influenciar a relação Executivo-Legislativo.

\section{Referências}

BRASIL. Constituição. Constituição da República Federativa do Brasil. Brasília, DF: Senado, 1988.

BRASIL. Presidência da República. Emenda Constitucional n. 86, de 17 de março de 2015. Altera os arts. 165, 166 e 198 da Constituição Federal, para tornar obrigatória a execução da programação orçamentária que especifica. Brasília: 2015. Disponível em: http://www.planalto.gov.br/ccivil_03/constituicao/Emendas/Emc/emc86.htm. Acesso em: 22/12/2019.

DINIZ, V. PEC do orçamento impositivo: um sonho que virou realidade? 2016. Dissertação (Mestrado em Ciência Política) - Programa de Pós-Graduação em Ciência Política, Universidade de São Paulo, São Paulo, 2016.

FIGUEIREDO, A; LIMONGI, F. Executivo e legislativo na nova ordem constitucional. Rio de Janeiro: Editora FGV, 1999.

FIGUEIREDO, A; LIMONGI, F. Incentivos eleitorais, partidos e política orçamentária. Dados - Revista de Ciências Sociais, Rio de Janeiro, v. 45, n. 2, p. 303-344, 2002.

FIGUEIREDO, A; LIMONGI, F. Política orçamentária no presidencialismo de coalizão. Rio de Janeiro: FGV, 2008.

FIGUEIREDO, A; LIMONGI, F. Processo orçamentário e comportamento legislativo: emendas individuais, apoio ao Executivo e programas de governo. Dados - Revista de Ciências Sociais, Rio de Janeiro, v. 48, n. 4, p. 737-776, 2005.

LUZ, J. Atuação partidária no presidencialismo brasileiro: $\mathrm{O}$ caso das emendas individuais orçamentárias. In: ENCONTRO ANUAL DA ANPOCS, 40, 2016, Caxambu. Anais [...]. Caxambu: ANPOCS, 2016. Disponível em: https://anpocs.com/ index.php/papers-40-encontro/st-10/st19-7/10333-atuacao-partidaria-no-presidencialism o-brasileiro-o-caso-das-emendas-individuais-orcamentarias/file. Acesso em: 22/12/2019. 
MESQUITA, L. Emendas ao orçamento e conexão eleitoral na Câmara dos Deputados. 2008. Dissertação (Mestrado em Ciência Política) - Programa de PósGraduação em Ciência Política, Universidade de São Paulo, São Paulo, 2008.

PEREIRA, C; MUELLER, B. Partidos fracos na arena eleitoral e partidos fortes na arena legislativa: a conexão eleitoral no Brasil. Dados - Revista de Ciências Sociais, Rio de Janeiro, v. 46, n. 4, p. 735-771, 2003.

PEREIRA, C; MUELLER, B. Comportamento estratégico em presidencialismo de coalizão: as relações entre executivo e legislativo na elaboração do orçamento brasileiro. Dados - Revista de Ciências Sociais, Rio de Janeiro, v. 45, n. 2, p. 265-301, 2002.

PEREIRA, C.; RENNÓ, L. O que é que o reeleito tem? Dinâmicas político institucionais locais e nacionais nas eleições de 1998 para a câmara dos deputados. Dados - Revista de Ciências Sociais, Rio de Janeiro, v. 44, n 2, p. 323-362, 2001.

VOLPE, R. O papel das emendas parlamentares no presidencialismo de coalizão: análise da execução antes e após o orçamento impositivo (EC86/2015). Cadernos ALEGIS, Brasília, v. 2, n. 56, p. 83-118, 2019.

VOLPE, R; CAMBRAIA, T. A experiência do orçamento impositivo na lei de diretrizes orçamentárias para 2014. RBPO - Revista Brasileira de Planejamento e Orçamento, Brasília, v. 5, n. 2, p. 100-131, 2015.

Recebido em: 17/09/2019.

Aceito em: 10/11/2019. 